\title{
A rare and reversible cause of acute dilatation of the pancreatic duct
}
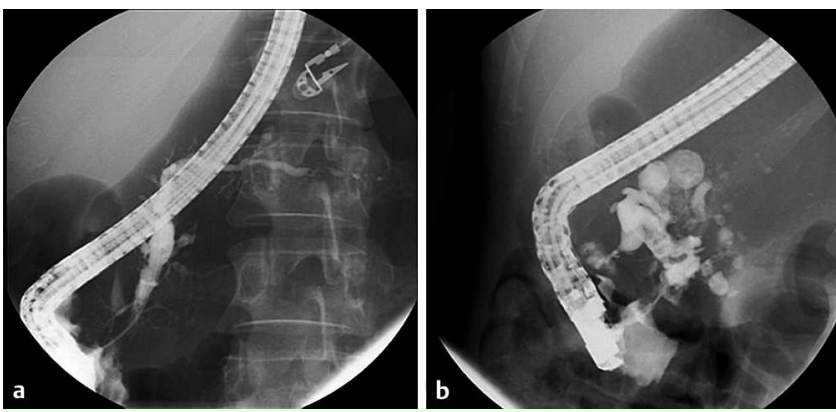

Fig. 1 Pancreatogram a 2 months before admission and after endoscopic intervention for removal of pancreatic duct stone and stenosis. b At admission, showing marked dilatation of the main pancreatic duct with inhomogeneous content and cystically dilated secondary branches.

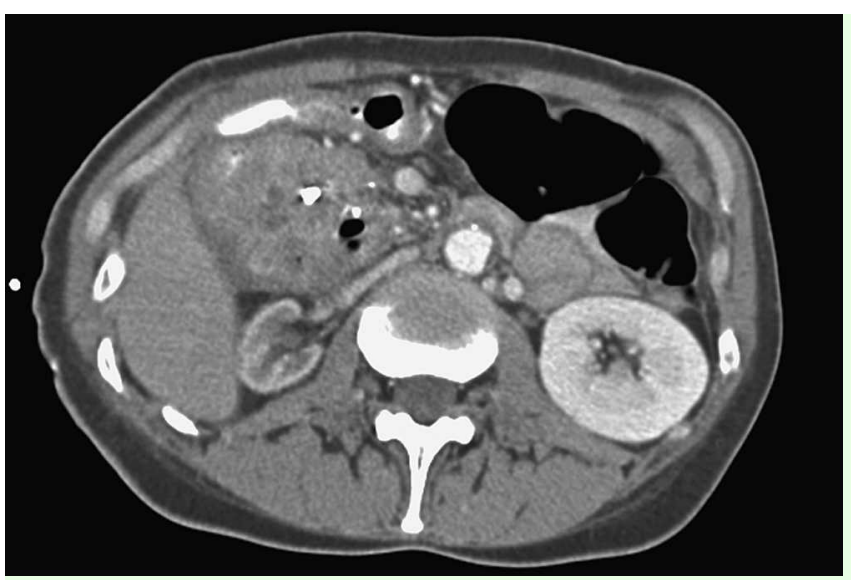

Fig. 2 Computed tomography of the pancreas at admission, illustrating congestive pseudotumoral head of the pancreas with cystically dilated side branches and compression of the common bile duct and duodenum.

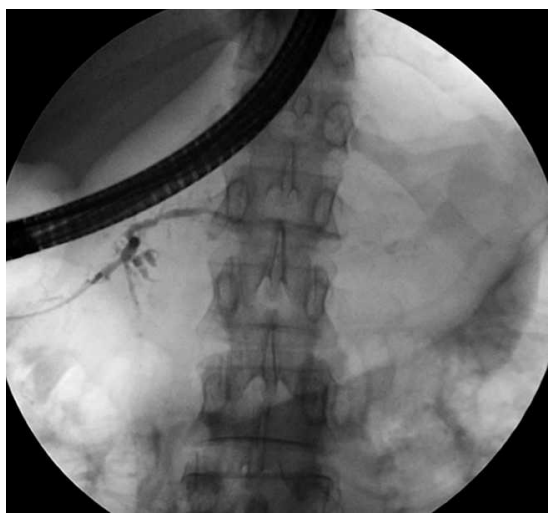

Fig. 3 Control pancreatogram 14 days after admission, showing restoration of the main pancreatic duct.

A 50-year-old woman with idiopathic chronic pancreatitis was treated endoscopically at our institution at the end of 2006 for a pancreatic duct stone and stenosis. After stone removal and temporary stenting, the main pancreatic duct returned to normal ( $\bullet$ Fig. 1 a). In March 2007, a cholecystectomy was performed after an acute cholecystitis had occurred in January 2007.

In May 2007, she was admitted with upper abdominal pain irradiating towards the back. Clinical examination revealed tenderness at the left hypochondrium and jaundice. Biochemical work-up showed marked inflammation (white blood cell count $15000 / \mathrm{mm}^{3}$, C-reactive protein $132 \mathrm{mg} / \mathrm{l}$ ), and cholestasis (bilirubin $6 \mathrm{mg} / \mathrm{dl}$ ). The patient was scheduled for endoscopic retrograde cholangiopancreatography, which demonstrated a congested periampullary region with massive evacuation of pus after cannulation of the Wirsung. Pancreatography showed pronounced dilatation of the main pancreatic duct with inhomogeneous content and cystically dilated secondary branches (๑ Fig. 1b). Computed tomography scan of the pancreas confirmed a congestive pancreatic head with pseudo-tumoral aspect, cystically dilated side-branches, and secondary compression of the extrahepatic bile duct ( $\odot$ Fig. 2). Cytology and Ziehl-Nielsen staining of aspirated pus were negative. Microbial culture documented the presence of Staphylococcus aureus and Streptococcus anginosus. Antibiogram-directed antibiotic treatment was initiated with penicillin and levofloxacin, leading to rapid recovery. Control pancreatography after 14 days showed complete restoration of the pancreatic duct without evidence of (sub)obstructive lesions ( Fig. 3).. In conclusion, we report the case of a bacterial infection of the main pancreatic duct and its side branches, leading to a transient pronounced dilatation of the pancreatic duct with massive evacuation of pus from the papilla. This is a rarely reported $[1,2]$ entity involving a chronically damaged pancreas, pancreatic outflow obstruction, and subsequent bacterial infection. The pathogenesis of this syndrome in this patient might be related to previous endoscopic interventions for chronic pancreatitis, although lymphatic and hematogeneous bacterial spread from a previously existing acute cholecystitis or intercurrent infection cannot be completely excluded.

\section{Endoscopy_UCTN_Code_CCL_1AZ_2AG}

\section{W. Laleman, M. Radwan, W. Van Steenbergen}

Unit for Liver, Biliary and Pancreatic Diseases, University Hospital Gasthuisberg, Catholic University of Leuven, Leuven, Belgium

\section{References}

1 Tajima Y, Kuroki T, Susumu S et al. Acute suppuration of the pancreatic duct associated with pancreatic ductal obstruction due to pancreas carcinoma. Pancreas 2006; 33: 195-197

2 Weinman DS. Acute suppuration of the pancreatic duct. Gastrointest Endosc 1995; 41: $268-270$

\section{Bibliography}

DOI 10.1055/s-2008-1077335

Endoscopy 2008; 40: E183

(c) Georg Thieme Verlag KG Stuttgart · New York . ISSN 0013-726X

\section{Corresponding author \\ W. Laleman, MD, PhD}

Unit for Liver, Biliary and Pancreatic Diseases University Hospital Gasthuisberg

Catholic University of Leuven

Herestraat 49

3000 Leuven

Belgium

Fax: +32-16-344387

wim.laleman@uz.kuleuven.ac.be 